\title{
Consecuencias culturales y políticas para los movimientos migratorios: estereotipos y prejuicios entre México y
} Centroamérica

\author{
Recepción: 15-09-2016 / Aceptación: 28-11-2016
}

Mariana Rodrigues Lopes lopesmariana2004@ig.co.br

Sueñan las pulgas con comprarse un perro y sueñan los nadies con salir de pobre [...] Los nadies [...] los dueños de nada [...] que son aunque no sean [...]

Eduardo Galeano

\section{Resumen}

En este trabajo se analizan los estereotipos y prejuicios presentes en las relaciones políticas y culturales entre México y Centroamérica y su impacto en el contexto de las migraciones centroamericanas hacia los Estados Unidos, a partir de la novela Amarás a Dios sobre todas las cosas (2013), del escritor mexicano Alejandro Hernández. Esta reflexión forma parte de una discusión más amplia que estamos desarrollando en nuestra tesis doctoral sobre las migraciones centroamericanas hacia los Estados Unidos y sus representaciones en la literatura centroamericana contemporánea. Estas relaciones se remontan al periodo precolombino, cuando casi toda la región conocido hoy día como Centroamérica y buena de parte del territorio mexicano, conformaban el territorio conocido como Mesoamérica. A partir de ese momento, dichas relaciones han tomado rumbos distintos, y se han convertido en una relación de amor y odio que se refleja, de manera muy acuciante, en el tratamiento a los migrantes centroamericanos en su tránsito por México, sobre todo en los últimos años. La novela reelabora estas relaciones mostrando su impacto en la vida cotidiana de los migrantes centroamericanos en su paso por México. Nuestro objetivo es mostrar que dichas relaciones van más allá del imaginario que tienen los mexicanos respecto a los centroamericanos y viceversa.

Palabras clave: Centroamérica, México, migración, prejuicios, violencia, cultura

\section{Abstract}

This paper analyzes the stereotypes and preconceptions present in political and cultural relations between Mexico and Central America, and their impact in the context of Central American migrations to the United States, through the novel Amarás a Dios sobre todas las cosas (2013), by the Mexican writer Alejandro Hernández. The reflection is part of a broader discussion that we are carrying out in our doctoral thesis, which deals with Central American migrations to the United States and their representations in contemporary Latin American literature. These relations go back to the pre-Columbian period when the region, now known as Central America and good of part of the Mexican territory, formed the area known as Mesoamerica. Since then, these relations have taken different courses, and have become a relationship of love and hate, as it is reflected in the treatment of Central American migrants in their transit through Mexico, especially in the last years. The novel re-elaborates these relations showing their impact in the daily life of the Central American migrants. Ourpurpose is to show that these relations go beyond the imaginary that Mexicans have with respect to Central Americans and vice versa.

Keywords: Central America, Mexico, migrations, preconceptions, violence, culture 


\section{Introducción}

Con la ruptura de la cohesión territorial, política y cultural que se llevó a cabo con la llegada de los españoles en el siglo XVI, en dichos territorios la vida de los pueblos que vivían en ellos cambió para siempre, ya que pasaron a vivir bajo nuevos patrones políticos y culturales impuestos por la administración de la Corona Española. En este contexto, hubo un cambio radical no solo en lo concerniente a la fragmentación del territorio y la cohesión política sino también de las culturas originarias que han pasado por un proceso de hibridación que se ha desarrollado a través de la introducción de la cultura española, europea, blanca, además de la inserción de esclavos africanos. En este sentido, todo el territorio que hoy conforma México pasó a ser conocido con Nueva España, y Centroamérica quedaría subordinada, en alguna medida, a este Virreinato, administrado por el poder colonial español. La nueva división territorial y la fragmentación sociocultural de esta región, causaron graves problemas para los pueblos originarios y fueron la base para el desarrollo de las relaciones políticas y culturales que actualmente se desarrollan en la región, como veremos a lo largo de este texto.
Mientras tanto, el territorio que hoy conocemos como México ha desarrollado el papel de centro de esta periferia. Cabe recalcar que Centroamérica era considerada periférica, por su condición de región pobre que no poseía minerales preciosos, como en los territorios anteriormente mencionados donde eran abundantes, mientras su riqueza se concentraba en la fuerza de trabajo indígena.

Siendo una región pobre, era considerada por los españoles, como Los Confines, o sea, una región de poco interés para la Corona Española:

Centroamérica era una región marginal dentro de una marginalidad mayor, o sea, América, especialmente el virreinato de Nueva España del cual formaba parte directamente (como se ha mencionado). Por otra parte, México, por su condición de centro económico y cultural del poder colonial español, ocupaba una posición privilegiada.

En este sentido, Amarás a Dios sobre todas las casas es una novela muy reciente en la que se refleja, de manera muy acuciante, toda la problemática que ha marcado las relaciones políticas y culturales entre México y Centroamérica a lo largo de siglos como mostraremos en nuestro texto. Esas son dos razones por las cuales la hemos seleccionado
Como señala el crítico y escritor guatemalteco-costarricense Rafael Cuevas Molina (entrevista, 2015), el territorio centroamericano, conocido en el principio de la colonización española como Los Confines y, posteriormente, como Capitanía General de Guatemala, actualmente Centroamérica, era visto por los colonizadores como la "periferia" del virreinato de Nueva España.
[...] la situación de Centroamérica también ha sido determinada como una relación de marginación en una marginalidad mayor porque desde el período colonial fue parte de una estructura mayor que fue el virreinato de Nueva España y no éramos la parte central del virreinato, éramos lo que en la colonial se llamaba Los Confines (Cuevas Molina, entrevista, 2015). 
para su análisis: su actualidad y el tratamiento que hace del tema de la migración centroamericana, convirtiéndolo en un texto de gran importancia, dentro de la ya amplia serie literaria, dedicada al tema de la migración, así como por su valor documental. Ciertamente hay otro tipo de producción audio visual muy importante, pero no viene al caso en esta investigación, ya que nuestro objetivo es trabajar sólo con la novela Amarás a Dios sobre todas las cosas.

Este artículo está organizado en dos partes: La primera hace énfasis en el tema de las relaciones entre México y Centroamérica, desde el período precolombino y sus cambios a lo largo de la historia. En la segunda se expone el estado actual de estas relaciones, de manera especial en el contexto de las migraciones centroamericanas hacia los Estados Unidos, en su paso por México, tal como 12 como es reelaborada, desde el punto de vista literario, en la novela Amarás a Dios sobre todas las cosas.

Para empreender dicho análisis nos fundamentamos en los estudios sociocríticos planteados por el crítico francés Edmond Cros, sobre todo la relación entre literatura y sociedad, puesto que de acuerdo con esa teoría la obra de arte es una práctica social que está directamente ligada a los imaginarios, a las mentalidades, a las ideologias de una época. La sociocrítica evalua los discursos de un momento histórico específico, por medio de las axiologias de los personajes, de los temas abordados y de las formas utilizadas. En ese sentido, pretende realizar una lectura de las obras literarias ubicándolas en el marco de un tiempo y un espacio determinados, por lo que se hace necesario tener en cuenta los hechos literarios a través de la historia en las diferentes sociedades. Eso conlleva, hacer un análisis de la relación entre literatura y sociedad, razón por la que la sociocrítica tiene como eje central el estudio de los contextos de las diferentes épocas, donde los autores escribieron sus obras y lo que nos transmiten con ellas. En este sentido, en su Diccionario de términos asociados en la teoria literaria, María Amoretti define la Sociocrítica de la seguiente manera: 'Es el estudio del estilo como mediación de la socialidad. Trata de desprender, por medio de una semiologia crítica de la ideologia, el logos social implícito en todo texto literário [...] (Amoretti: 1992; 112)"

De igual manera, nos apoyamos en los Estudios Culturales (Estudios de la Cultura), sobre todo los de Homi K. Bhabha acerca del reconocimiento de las nuevas minorías en las sociedades actuales, de manera particular, en su libro "Nuevas minorías, nuevos derechos: notas sobre cosmopolitismo vernáculos", donde destaca a los migrantes como parte de estas minorías.

Partimos del criterio sustentado en la posibilidad de un diálogo productivo, entre estos dos ejes teóricos. Tanto la Socio crítica como los Estudios Culturales, ayudan a la comprensión de los hechos históricos, políticos, sociales y culturales, tal como se reelabora en la novela de la cual nos ocupamos.

\section{Una metrópoli dentro de la periferia}

México ha sido el centro de una periferia mayor y Centroamérica la periferia de este centro. Esta posición de inferioridad, explica sobremanera las relaciones construidas en estos territorios, reflejada en la actualidad, en los diversos contextos en que ambas expresiones socio culturales, están involucradas. Sobre todo, en lo concerniente a los problemas ligados a los procesos migratorios, donde el tratamiento a las personas centroameri- 
canas que emigran, evidencia los cambios que dichas relaciones han sufrido, de manera particular, en los últimos 20 años.

Estas relaciones han estado marcadas por conflictos en algunos momentos. Del mismo modo, por episodios de hermandad y solidaridad recíproca, México- Centroamérica. Un ejemplo de esto último, es la beligerancia de México en el concierto internacional, durante los conflictos armados en la región, entre las décadas del 60 y 90 del siglo pasado, que dejaron un saldo de millares de muertos, desparecidos y refugiados.

En este período, la solidaridad llevada a cabo desde México, fue fundamental en muchos sentidos. En primer lugar, porque recibió a millares de migrantes, refugiados y exiliados, guatemaltecos fundamentalmente, que huían de los escuadrones de la muerte en su país. En segundo lugar, por su postura firme, con gran sentido de independencia y respeto a las soberanía de los pueblos, frente al gobierno norteamericano involucrado de manera directa en los conflictos armados en Centroamérica, buscando una salida pacífica a los conflicto ${ }^{1}$. En tercer lugar, la creación del Grupo Contadora, instancia multilateral propuesta por México y Colombia (1983) integrada por Panamá y Venezuela, representó una importante iniciativa de paz para América Central, donde el gobierno azteca jugó una papel digno de encomio.

De fines de los años setenta a principios de los ochenta, la política de México hacia los países centroamericanos se puede caracterizar como una política activa que dio apoyo a los movimientos sociales en la región, se desarrolló de manera independiente con respecto a Estados Unidos y desempeñó un papel fundamental en la búsqueda de la paz en el área. El gobierno mexicano no solo debió hacer frente a una situación de guerra en el istmo centroamericano, que trajo consigo la presencia de decenas de miles de refugiados en su frontera sur, sino que tuvo que resistir las presiones de Washington y los embates de la opinión pública interna, que insistía en denunciar los costos de esta política.

[...] y, a partir de la creación del Grupo Contadora en 1983, se propuso emprender una acción conjunta con otros gobiernos latinoamericanos para alcanzar la paz en la región, aunque esta iniciativa a la postre no logró conseguir los objetivos planteados. En los años noventa, no obstante que México había volcado su interés hacia Estados Unidos con miras a la firma del Tratado de Libre Comercio con América del Norte (TLCAN), el gobierno mexicano tuvo una participación activa en las negociaciones para alcanzar la paz, primero en El Salvador, en 1992, y luego en Guatemala, en 1996 (Toussaint Ribot: 2015; 174)

En épocas distintas en que se dieron los conflictos armados, los migrantes centroamericanos podían cruzar el territorio mexicano, sin preocupación alguna por los controles migratorios. En este contexto, México asume el papel de país de acogida y de paso de migrantes centroamericanos hacia los Estados Unidos. Sin embargo, el incremento de estos migrantes que diariamente cruzaban la

\footnotetext{
1 Los Estados Unidos estaban involucrados directamente en los conflictos, ofreciendo dinero, entrenamiento militar, incluyendo la fundación de bases militares en la región, entre las cuales se destaca la famosa base Palmerola en Honduras, además de diversas maniobras creadas para combatir los movimientos de lucha en Centroamérica.
} 
frontera, llevó a sus autoridades a poner atención al flujo migratorio de trabajadores, refugiados y migrantes en tránsito. Esto dio pie a cambios en sus políticas migratorias, poniendo énfasis en la movilidad, partiendo del criterio diferenciadores de migrantes y refugiados:

[...] A lo largo del siglo XX los trabajadores guatemaltecos cruzaban la frontera hacia México sin ningún control por parte de las autoridades migratorias. Durante la década de los ochenta, el conflicto armado en Centroamérica y la consecuente salida de refugiados hacia México como lugar de destino o espacio de tránsito hacia Norteamérica motivaron la atención de las autoridades mexicanas a los flujos de refugiados, trabajadores transfronterizos y migrantes en tránsito, especialmente aquellos procedentes de Guatemala. En consecuencia, la formulación de lineamientos de política de aquellos años consideró tanto a los refugiados como a los trabajadores y migrantes temporales y permanentes (Anguiano Téllez: 2010; 170)

La solidaridad mexicana, expresada en millares de refugiados, exiliados y migrantes centroamericanos, durante los conflictos armados, es digna de admiración y respeto. No obstante, como señala Anguiano Téllez (2010: 173-174), finalizados los conflictos, estas relaciones han tomado otros rumbos, especialmente después de los atentados de 11 de septiembre de 2001 y de la construcción del muro, en algunas partes de la frontera, de México con Estados Unidos (2005). Un contexto complejo, que llevó a las autoridades norteamericanas a cambiar de manera radical, sus políticas migratorias, aumentando los controles en la frontera con México y exigiendo a su gobierno, mayores controles en la frontera sur con Guatemala.
En este mismo período fue implementado por el gobierno mexicano El Plan Frontera Sur (2001 2003), en su frontera con Belice y Guatemala con el propósito de controlar los flujos migratorios, el tráfico de armas y modernizar del control fronterizo:

... perfeccionado "sus actividades de identificación, detención y repatriación de migrantes centroamericanos y de otras nacionalidades que ingresaron en forma irregular por su frontera sur". El Plan Frontera Sur incluía el establecimiento de dos cinturones de inspección y control migratorio que se extenderían de la Costa de Chiapas, en el Océano Pacifico, a la de Tabasco, en el Golfo de México, y, desde la costa de Oaxaca hacia el sur de Veracruz y la costa de Tabasco. De igual forma, se desplegaron actividades de inspección en las costas del Golfo y del Pacífico incorporando a las entidades mexicanas del sureste y la península de Yucatán. La colaboración incluyó a las autoridades estatales y migratorias dependientes de la Secretaria de Seguridad de Gobernación, como el Instituto Nacional de Migración, y se extendía a autoridades policíacas dependientes de la Secretaria de Seguridad Pública, el Centro de Investigación y Seguridad Nacional y la Procuraduría General de la República (Artola, 2006; Casillas, 2006) (Anguiano Téllez: 2010; 173- 174)

De acuerdo con la misma autora (Anguiano Téllez: 2010), además del Plan Frontera Sur, en 2004, se estableció el Sistema Integral de Operación Migratoria (SIOM), que pretendía controlar los ingresos y flujos, repatriación y permisos de residencia, obtención de nacionalidad y trámites migratorios, a cargo del Instituto Nacional de Migración, institución 
que ha sido denunciada por diversas organizaciones de defensa de los migrantes, sobre todo por la organización WOLA (2016), de estar involucrada en corrupción. En este sentido, el protagonista de la novela Amarás a Dios sobre todas las cosas, la describe como una institución que no inspira confianza a los migrantes, debido a la corrupción de algunos de sus empleados, quienes están mancomunados con los grupos criminales que persiguen a los migrantes, como veremos más adelante en la novela.

Este sistema se incorporó en 2005 al Sistema de Seguridad Nacional y pasó a conocerse como Propuesta de politica migratoria integral en la frontera sur de México. El objetivo central del gobierno mexicano, con dicha propuesta, era "salvaguardar" la seguridad de su frontera sur a través de nuevas medidas de control migratorio, pero la experiencia ha mostrado que dicha propuesta ha fallado, ya que el nivel de inseguridad en la frontera sur ha aumentado.

Con base en la propuesta anterior, y contando con el apoyo de militares y policías, para el 2006 se habían establecido 25 retenes de carretera y 21 controles del Instituto Nacional de Migración, entre la frontera sur mexicana y Ciudad de México, afectando, de manera significativa, el paso de los migrantes centroamericanos, de otras partes de América Latina y del mundo, por el territorio mexicano.

Además de los referidos planes y medidas de control, acerca de la movilidad transfronteriza entre México y Guatemala, cabe agregar el Plan Alian- za para la Prosperidad y Seguridad del Triángulo Norte (2014)2. El entonces presidente Barack Obama, convocó a los presidentes de Guatemala, Honduras y El Salvador para la elaboración de un plan regional, contando con la colaboración técnica del Banco Interamericano de Desarrollo -BID. Dicho plan fue elaborado en seis meses, pasando a ser ejecutado en los tres países, a partir del 2015, generando posiciones encontradas respecto de su enfoque, objetivos y efectos de su aplicación:

Aunque la mayor parte de la ayuda de la Alianza para Prosperidad fue asignada a las iniciativas de desarrollo, el hecho de que Estados Unidos continúa financiando proyectos como CARSI enciende alarmas en la población. Estados Unidos destinará \$348,5 millones de dólares, casi el 46 por ciento del total de los fondos de la Alianza para la Prosperidad a CARSI; la cual ha sido ampliamente criticada por militarizar la seguridad y usar mecanismos de cooperación multilaterales poco transparentes $\mathrm{y}$ que dan resultados perjudiciales. Hay que tener en cuenta que CARSI deriva de la Iniciativa Mérida, la cual fue inicialmente diseñada para ayudar a los gobiernos locales a combatir el tráfico de drogas en México y América Central, al trabajar en la creación de instituciones, el estado de derecho y la protección marítima entre otras iniciativas.

En el año 2010, la dimensión de América Central del Plan Mérida se transformó en lo que es ahora CARSI (García: 2016; 5)

2 Plan Alianza para la Prosperidad y Seguridad del Triángulo Norte - El Plan Alianza para la Prosperidad de los países del Triángulo Norte - PAPTN- que comenzó a gestarse desde el año 2014, consiste en un conjunto de medidas para promover el desarrollo de la región, que permita construir las condiciones propicias en Guatemala, Honduras y El Salvador de manera tal que evite la migración masiva de personas de estos países hacia Estados Unidos. El proyecto, tuvo como marco la crisis de la niñez migrante no acompañada que puso en evidencia, de manera contundente, el drama de la migración en la región. En aquel contexto, el mandatario estadounidense Barack Obama convocó a los presidentes de Guatemala, El Salvador y Honduras para comenzar a construir un plan regional con la asistencia técnica del Banco Interamericano de Desarrollo -BID-Dicho plan se elaboró en los meses posteriores y desde el año 2015 se ejecutan acciones en los tres países, generando posiciones encontradas sobre su enfoque, los propósitos y efectos de su aplicación (Foro-Debate Guatemala, 25 de mayo de 2016) 
También podríamos mencionar el Plan Puebla Panamá o Plan Mesoamérica (2001-2008), el Plan Colombia (1999), la Iniciativa de Mérida (2008), inicialmente conocida como Plan México, y la Iniciativa Regional de Seguridad para Centroamérica (CARSI). Todos estos planes desarrollados en la región, a pesar de haber sido creados bajo el discurso de que mejoraría la movilidad transfronteriza, más bien han contribuido a empeorarla. En los últimos años, la pobreza y la violencia exacerbada, han causado graves problemas y llevado a millares de personas a migrar hacia los Estados Unidos.

La implementación del Plan Alianza para la Prosperidad y Seguridad del Triángulo Norte, propuesto por Obama, con el fin de encontrarle respuesta al problema de los miles de niños indocumentados, quienes sin compañía de familiares adultos, intentaban cruzar la frontera entre México y Estados 16 Unidos. En el 2014, este hecho fue considerado como una crisis humanitaria, siendo un ejemplo del fracaso de estos planes para Centroamérica, de manera especial para El Salvador, Honduras y Guatemala. Este Plan Alianza para la Prosperidady Seguridad de Centroamérica ha sido muy criticado y mal visto por investigadores, activistas defensores de los migrantes y población en general.

Quedan claros los efectos negativos de dichos planes, con el aumento de la migración. Millares de personas no ven aún otra salida a sus dificultades a no ser dejando sus patrias. Esta situación crea serios problemas, dado que se hace cada vez más difícil, para los centroamericanos, alcanzar suelo estadounidense, como se aprecia en la novela en estudio.

En este contexto, México ha desempeñado un papel importante, no únicamente como "buen administrador de las órdenes de Estados Unidos", --como apunta Alejandro Solalinde ${ }^{3}$-- sino por su actitud ante los migrantes centroamericanos, al negarles derechos humanos básicos. En este sentido, cuando se trata de Estados Unidos, México asume un papel sumiso, plegándose a las medidas adoptadas por Estados Unidos, al cumplirla a cabalidad.

Cuando el asunto tiene que ver con problemas migratorios de ciudadanos centroamericanos, al sur, México asume una actitud intransigente y poco amistosa, con los gobiernos de estos países vecinos. La situación es grave, de acuerdo con el padre Solalinde (2016), en los últimos años, muchos cónsules centroamericanos, comprometidos la mayoría de ellos con los problemas migratorios en la región, se han quejado por el tratamiento recibido de parte de las autoridades mexicanas.

En este contexto, la novela bio ficcional Amarás a Dios sobre todas las cosas reelabora, de manera muy acuciante, los prejuicios, la exclusión, la discriminación y el abuso de los mexicanos hacia ese "otro" migrante centroamericano. En ella, se evidencian los niveles de crueldad que sólo la ficción es capaz de representar, con tanto realismo como se verá a continuación. 


\section{Entre el dolor y la esperanza: la representación del migrante centroamericano en la novela Amarás a Dios sobre todas las cosas}

Hay quienes migran porque en Centroamérica la mitad de la población vive bajo la linea de la pobreza. Hay quienes migran para reencontrarse con sus familiares en el Norte. Pero hay también quienes, como los hermanos Alfaro, más que migrar, buyen. De repente, en su pequeño mundo de El Salvador empezaron a caer cadáveres. Cada vez, más cerca. Luego, una amenaza. Este es el viaje de Auner, Pitbully El Chele, unos migrantes que nunca anbelaron Estados Unidos

Óscar Martínez, 2010

En la novela, Amarás a Dios sobre todas las cosas ${ }^{4}$, Walter narra su historia y la de su familia: Milla Funes, de origen hondureño. Con ello se narra la historia de otros migrantes hondureños, de otras partes de Centroamérica y sus intentos por llegar a los Estados Unidos.

Estructurada a partir de cuatro viajes, la trama de la novela es compleja. El primer viaje es emprendido por Wilbert, jefe de la familia, su hijo mayor del mismo nombre y su hermano menor Valente. Debido a la miseria en la cual se encuentran en Honduras, resuelven viajar como indocumentados hacia los Estados Unidos. Una vez llegados a México, Valente desaparece, Wilbert padre es deportado y Wilbert hijo, después de mucho tiempo, consigue avisarle a su familia que ha llegado a los Estados Unidos.

Con el fracaso del primer viajar y el aumento de la pobreza en Honduras, Walter, su padre Wilbert, su hermano Waldo y sus primos Lucía y Danilo, resuelven emprender un segundo viaje hacia el Norte. En México conocen a El Profeta y a Elena de quien Walter se enamora, así como a otros migrantes centroamericanos. Durante el trayecto en La bestia, Waldo pierde las piernas y se queda paralítico y Elena es violada. En este contexto, Wilbert (padre) desiste continuar el viaje para buscar a Waldo, quien se encuentra en un albergue. El resto son deportados por las autoridades mexicanas.

Ante la situación económica desesperante, y sintiendo en carne propia el rechazo de Elena y su alejamiento, quien después de haber sufrido la violación, se siente sucia, Walter resuelve intentar llegar a Estados Unidos nuevamente. Esta vez viaja con su primo Luis, sus amigos Charles y Danilo, además de varios migrantes, con los cuales se encuentran por el camino, convirtiéndose en su guía.

En uno de los puntos del trayecto por México son secuestrados por un grupo de mexicanos. Mientras están encerrados, llega otro grupo de migrantes, entre los cuales se encuentra su amigo de viaje El Profeta, quienes también padecen de secuestro. En un contexto de crueldad y humillación Walter, El Profeta y Gigante intentan huir en busca de ayuda. En el intento, Gigante es asesinado por los secuestradores, pero Walter y El Profeta consiguen huir y piden ayuda al ejército.

Al ser rescatados, Walter llama a su familia y a Elena, quien le había aceptado de nuevo, al convencerse que lo amaba mucho. El joven descubre que su madre está ciega de un ojo y perderá el otro si no se le hace una cirugía. En este contexto, Walter y El Profeta resuelven viajar a los Estados

4 Incluimos un resumen de la novela en nuestro artículo porque buena parte de la gente que lo leerá no la conoce. En este sentido, un resumen básico ayuda a entender mejor la problemática representada en dicha novela. 
Unidos otra vez. La novela termina cuando ellos están sentados en una plaza, en la región de San Fernando, Estado de Tamaulipas, ubicado en el noreste de México.

En la novela los procesos migratorios se inician en Honduras y tiene como punto de llegada los Estados Unidos, donde se supone habría mejores condiciones de empleo, aunque paradójicamente, se añore el regreso a su propia tierra. En Amarás a Dios sobre todas las cosas, la utopía para los migrantes no es Estados Unidos sino su propia patria. El sueño de este migrante no es echar raíces en el país del Norte, sino, más bien, retornar a su patria con los recursos necesarios para vivir con dignidad. O sea, ser reconocido en su propio país como sujeto digno de los derechos básicos indispensables para la vida humana.

Como parte de este proceso migratorio, se debe de cruzar Guatemala y México. El problema para los migrantes no es que Guatemala sea el punto inicial o intermedio, el problema es México. En este contexto, México se ha ganado una imagen negativa, por las extorsiones, el maltrato, hasta la muerte que padecen los migrantes ¿Pero qué piensan de los centroamericanos? ¿Por qué pasa eso? ¿Por qué tan cerca y tan distantes al mismo tiempo? Una buena parte de México forma parte de Mesoamérica, cuenta con más recursos y tienen, para decirlo así, un "valor simbólico" importante en relación con sus vecinos del sur. La rivalidad se extiende incluso al fútbol, pues las selecciones y los equipos de fútbol de los países de Centroamérica, a menudo son eliminados por equipos mexicanos. Las primeras referencias hechas por el protagonista de la novela al tratar de estas relaciones así lo consignan:
[...] Es el gigante económico, el país inmenso, el hermano mayor de una familia rota. Centroamérica cabría diez veces dentro de su territorio. Es también el enemigo número uno en el fútbol, el gigante de la Concacaf $^{5}$, el que siempre nos vapulea y nos fusila a balonazos sin misericordia. Aunque eso era antes. En tiempos recientes batallan los mexicanos para ganarnos, a pesar de que algunos de sus seleccionados militan en equipos de Europa y a pesar de los salarios inmensos que se pagan en la liga mexicana. Siempre queremos ganarles y la mayoría de las veces nos quedamos con las ganas. El sueño mayor en el fútbol es ganarle a México en el Azteca. No hay centroamericano que no haya albergado esa ilusión. Cien mil mexicanos gritando su superioridad y nosotros haciéndoles goles en su propia casa (Hernández: 2013; 50)

Lo que más llama la atención en el fragmento anterior, no es el hecho de que México sea el número uno en el fútbol en la zona, sino que sea el gigante económico y el hermano mayor de una familia rota. ¿A cuál familia rota se refiere el narrador de la novela? Para entender a qué familia se está refiriendo, es necesario entender los procesos históricos antes mencionados, donde México y Centroamérica han estado involucrados.

La referencia a México como gigante, no deja de llamar la atención, principalmente cuando en los últimos años ha enfrentado serios problemas económicos. Comparado con Honduras, país de origen del protagonista y de la mayoría de los personajes de la novela, el país Azteca es un gigante en todos los sentidos. Siendo un gigante, ya no le 
interesa una familia pobre, de la que ha dejado de formar parte hace mucho tiempo. El protagonista sabe que es muy difícil que los centroamericanos superen a México, por eso la ilusión de ganarle en el fútbol, sobre todo en el Estadio Azteca, en su propia casa. Eso sería lo máximo, por lo menos en este aspecto, México dejaría de ser superior a ellos.

De lo anterior, se puede observar que en el imaginario centroamericano, México es siempre un escollo, un problema que los acompaña siempre, sea en el contexto de la migración, de la economía, del fútbol o en otros aspectos. Es el hermano mayor de una familia rota que no los acepta, que los rechaza, que los ve como invasores indeseados, que siente -podría decirse-- placer en maltratarlos.

La familia se ha roto en todos los sentidos y eso se refleja de manera cotidiana en la vida de los migrantes centroamericanos, en su paso por México. Durante toda la narrativa se observan los cuestionamientos de los migrantes acerca del comportamiento de los mexicanos con respecto ellos. Dichos cuestionamientos no están relacionados a las autoridades mexicanas o a los delincuentes, sino a los mexicanos en general puesto que, a lo largo de la novela, los personajes, y de manera personal el protagonista, está siempre buscando comprender el comportamiento de los mexicanos en relación a él y a sus compañeros migrantes. Pese a ello, las autoridades mexicanas y los delincuentes son los mayores problemas enfrentados por ellos:
Me aventaron los maras, me dijo, desde arriba del tren, porque no andaba dinero. Su voz venía desde la tierra de abajo. Se dio cuenta de que yo estaba despierto y empezó a contar. Iba con mi hermano y de pronto los vimos. Venían fuertes, agresivos, caminando sobre el techo. Era de noche y apenas los veíamos. Querían dinero y mujeres. Así venían gritando. Querían que les besáramos las manos, que les suplicáramos. Que nosotros, los hijos de nuestra chingada madre, tembláramos y lloráramos. Yo les dije No ando dinero, miren, y me saqué los bolsillos. Un grandote me jaló por el cuello, me escupió en la cara, me aventó. Y sentí el tajo en el brazo, caliente el tajo o el brazo o las ruedas, y un golpe en la cabeza, seco como la muerte en bruto [...] (Hernández: 201; 60-61)

Este es uno de los primeros momentos en la narrativa donde se empieza a expresar la violencia en el territorio mexicano en contra de los migrantes. Los maras o las maras ${ }^{6}$ es el nombre de algunos de los grupos criminales que actúan en Centroamérica (El Salvador, Honduras y Guatemala), México, Estados Unidos y Canadá, en menor medida. Son considerados como el terror de los migrantes indocumentados en su paso por México. Sin embargo, el gran villano de los personajes de la novela, no son las maras, sino los secuestradores mexicanos mancomunados con la policía, con el Instituto Nacional de Migración, o sea, con las autoridades mexicanas, las más de las veces corrup-

\footnotetext{
6 Las Maras tal como las conocemos actualmente son grupos de jóvenes involucrados con actividades criminales que surgen en Los Ángeles (Estados Unidos) durante el período de guerra civil en Centroamérica cuando muchos migrantes e hijos de migrantes, sobre todo salvadoreños, al sentirse discriminados, en la sociedad estadunidense, empiezan a encontrar en la bandas latinas, fundamentalmente mexicanas un espacio social y familiar que les confiere identidad, pertenencia, seguridad. Sin embargo, concluida la guerra, los Estados Unidos deportan esos jóvenes a países, para muchos de ellos, desconocidos, puesto que habían migrado niños o habían nacidos en Estados Unidos. Dichos grupos juntamente con Los Zetas, grupo criminal que formaba parte del cuerpo de élite del ejército mexicano actualmente son los grandes peligros enfrentados por los migrantes (Cuevas Molinas, entrevista, 2015)
} 
tas. Su condición de indocumentados, hace que los migrantes estén expuestos a todo tipo de abuso como subraya Bhabha (2013:69) "El problema del indocumentado, sin papeles - sans papier-, supone una condición simbólica, física y semiótica de invisibilización y borramiento [...]"

La narrativa avanza y el tratamiento de los mexicanos, en relación a los migrantes centroamericanos, va empeorando de acuerdo al contexto en los cuales se encuentran, sean estas las autoridades o los grupos delincuenciales, especialmente los secuestradores referidos. Ante este panorama, los migrantes cuestionan el comportamiento de los mexicanos con respecto ellos y las consecuencias de estar ocultándose en territorio mexicano:

[...] Por qué es tan difícil que nos dejen pasar por México sin perseguirnos, sin detenernos. A los mexicanos qué. Nada más queremos pasar. No les queremos quitar nada. Llegar a Estados Unidos. Si no fuera porque tenemos que andar escondiéndonos, Juana no se hubiera muerto [...] (Hernández: 2013; 77)

En esta parte de la narrativa, aparecen los primeros efectos de la persecución, a raíz de la muerte del personaje Juana, quien cae del tren intentando subir. El tren en la novela, no es un medio de transporte sino un personaje involucrado en una trama terrible. El tren parece la personificación del mal, pero también representa la única esperanza de llegar al Norte. El mismo tren que le segó la vida a Juana, es el que supuestamente llevará a sus compañeros a los Estados Unidos. La muerte de Juana, como la de otros migrantes en la novela, son hechos que les causa dolor a sus compañeros de viaje, expuestos todos ellos a circunstancia.
Nadie reclama los cuerpos de los fallecidos. El tren, así como el territorio mexicano en general, es tierra de nadie. Los muertos no pueden hablar acerca de lo que les pasó, los que están vivos, les gustaría hablar, pero se les prohíbe hacerlo. Como señala Sandoval (2015: 35) "La muerte por goteo no duele ni indigna a las esferas oficiales".

Por el contrario, las esferas oficiales, en muchos casos, son las responsables de dichos problemas. Desde las esferas estatales mayores, que dictan leyes y establecen controles migratorios, hasta las instancias menores de dichas esferas, como los agentes de migración, las estaciones migratorias, entre otras. En este sentido, la novela muestra que muchas de estas instituciones, en lugar de garantizar los derechos mínimos de los migrantes, los discriminan y los tratan como nadie:

[...] adormecido, ni se dio cuenta cuando dos agentes de la migración se acercaron. Lo levantaron por la axila y allí mismo lo madrearon. Sonreía el chavo mientras contaba Ya cachimbeado qué me van a hacer, pensaba, y que me reciben con más madrazo en la estación, que me llevaron a un cuarto oscuro y que esposan en barrote. Verdad, mierda. Como lo digo. Allí estuve cuatro días, sin agua y sin comida, de castigo. Pinche hijo de tu chingada madre, me decía el guardia que iba a verme. Para que te sueltes tienes que mamarme la verga, si no, ni agua, hijo de puta (Hernández: 2013; 88)

Los mismos oficiales de migración, quienes deberían proteger a los migrantes, los maltratan, los castigan, los humillan de la peor forma. Las dos últimas frases del fragmento, son un ejemplo claro de la total falta de respeto por el migrante, 
sobre todo cuando el guardia le dice que para que le deje en libertad, debe de succionar su pene, de lo contrario se quedará encerrado sin agua y sin comida. A partir de este momento, la narrativa empieza a mostrar las relaciones entre México y Centroamérica, marcada por el odio hacia el migrante centroamericano. Aunque se observa también, una vertiente de amistad y afecto de parte de algunos mexicanos, lo cual se recrea en los albergues y casas de apoyo a los migrantes, en diversas regiones de México. Dichos albergues, desempeñan un papel primordial en la vida cotidiana de los migrantes en territorio mexicano, es una de las ayudas más importantes con que cuentan.

En este sentido, podemos mencionar un número significativo de albergues que aparecen en la novela, existente en la vida real, siendo espacios de solidaridad y apoyo. Estos albergues son administrados por la Iglesia Católica en México. Están presentes en Estados Unidos, Canadá y Centroamérica. El Albergue del padre Flor es un ejemplo significativo:

Llegamos a la Casa de Padre Flor cuando ya oscurecía, después de andar varias horas, completamente mojados y llenos de lodo, porque en cuanto nos alejamos del Suchiate empezó a caer la lluvia como las de Honduras, primero abundante y refrescante en medio del sopor de la tarde y después antipática, devoradora, imparable [...] (Ibíd.: 2013; 53)

[...] Era bueno estar, de nueva cuenta, en una casa para migrante, como la de Tecún Umán. Puedes respirar, sentirse huésped de alguien, persona, Si quieren bañarse, ya va- mos a cenar, se pueden quedar dos días, si quieren pueden lavar su ropa, mañana veo si tenemos pantalones y camisas, por si no tiene remedio lo que traen (Ibíd.: 2013; 54)

El papel desarrollado por albergues como la Casa de Padre Flor es muy importante para los migrantes en territorio mexicano, principalmente porque son los únicos espacios con los cuales pueden contar. Espacios que además de la ayuda, les inspira confianza, al contrario de las instituciones del gobierno representadas en la novela como espacios de violencia, de maltrato y de humillación.

No obstante, estos centros de ayuda en el viaje, apenas representan un paliativo frente a una problemática que va más allá de la solidaridad. En realidad, dependen de las instancias gubernamentales, que pocos o nada están interesados en resolverla. Por el contrario, han cerrado sus fronteras, aunque esto no impide el cruce cotidiano de los migrantes por el río Suchiate:

Para los centroamericanos el río Suchiate es una remota imagen traspasada de generación en generación por debajo de la conciencia, sin palabras. Más que un río, un punto geográfico, es un símbolo de esperanza y despedida. Cuando se pasa el Suchiate uno está en México, nuestro vecino poderoso, alguna vez amigo y solidario, y últimamente hermano orgulloso y gringuero que quiere parecerse cada vez más a los gringos y menos a nosotros (Ibíd.: 2013; 50)

El río Suchiate ${ }^{7}$, más que un espacio físico es un espacio simbólico que se remonta a un pasado no muy lejano. Es sinónimo de esperanza, pero tam-

bién puede representar la muerte o la despedida 7 Cabe recalcar que en la frontera norte entre México y Estados Unidos también hay un río muy importante conocido como río Grande o río Bravo que suele ser un gran problema para los migrantes que intentan cruzarlo. En este sentido, al contrario del río Suchiate, que los migrantes suelen cruzar 
en la vida de muchos migrantes que lo cruzan. En su Diccionario de Simbolos, Becker interpreta el simbolismo de los ríos de la siguiente manera:

[...] por causa da importância para a fertilidade muitas vezes o rio é venerado como divindade, p. ex., entre os gregos e romanos como deus da masculinidade local. - Geralmente aparece em estreita relação simbólica com a água. Por causa do seu fluir, é símbolo do tempo e da transitoriedade, mas também de contínua renovação - A influência de todos os rios ao mar é considerado símbolo da união entre divindade e absoluto [...] (Becker: 2007; 235)

Si relacionamos la definición de Becker con el fragmento de la novela citado, podemos pensar con más claridad acerca de lo que significa el río Suchiate para los migrantes centroamericanos. Dicho río es símbolo de esperanza y renovación en sus vidas. Representa su pasado, pero también su presente y su futuro. La vida de estos migrante es como el agua de este río, corre en busca de un destino incierto, pero lleno de esperanza.

Por eso, a partir del momento que los personajes cruzan el Suchiate, además de esperanza, necesitan coraje, resistencia física y emocional y, en muchos momentos, resignación para enfrentar su vida en tierras mexicanas. Cruzar el río es apenas el inicio de una peregrinación, muchas veces esta travesía termina en tragedia, como la muerte de Juana y de otros personajes.

Para los personajes, México es el gran problema a enfrentar, pero también representa la esperanza, o aliciente de una vida mejor, al llegar a los Estados
Unidos. Cabe recalcar, el objetivo de muchos de los migrantes no es quedarse en Estados Unidos, sino trabajar, reunir dinero y regresar a su país de origen, considerada la verdadera Tierra Prometida a alcanzar.

Para hacer realidad sus objetivos, los migrantes deben cruzar México, transformado en los últimos años, como un lugar cruel, por el comportamiento de sus instituciones y la actitud de ciertas personas. Como afirma el protagonista de la novela, son cada vez más gringuero.

Aunque hay que reconocer que los migrantes mexicanos indocumentados, sufren la misma discriminación y violencia en los Estados Unidos o en su frontera norte. En este sentido, el gran villano de los personajes no son los Estados Unidos, porque la mayoría de ellos nunca llegan a ese país, el verdadero problema para los migrantes es México: “[...] Por qué es tan difícil que nos dejen pasar por México sin perseguirnos, sin detenernos. A los mexicanos qué. No les queremos quitar nada. Nada más queremos pasar. Llegar a Estados Unidos [...] (Hernández: 2013; 77)"

Como se ha señalado, México es visto como un escollo, como una barrera que no les permite a los migrantes llegar a su destino. Entre las preguntas más comunes que se hacen los migrantes centroamericanos están: ¿por qué nos tratan así? ¿Qué les hicimos para merecer ese trato? ¿Por qué nos tratan tan mal? Para ellos cruzar el territorio mexicano no debería ser un problema, están apenas de paso. Sin embargo, para los mexicanos, especialmente para las autoridades, eso es un delito muy grave. En este sentido, la novela Amarás a Dios sobre todas las cosas performatiza ese imaginario que 
existe entre los centroamericanos: la relación de amor y odio recíproco.

Como hemos señalado, las relaciones actuales entre México y Centroamérica están influenciadas, directa $\mathrm{O}$ indirectamente por relaciones con Estados Unidos. A lo largo de la novela se observa que México aparece como el villano mayor de los migrantes, aunque por detrás está Estados Unidos, quien dicta las reglas del juego. Frente a esto, ¿cómo enfrentar a estos dos monstruos estando en situación de vulnerabilidad?

Algo paradójico y difícil de entender, es la actitud del gobierno mexicano, de seguir de manera obediente las políticas migratorias impuestas por Estados Unidos, obstaculizando y vejando a los migrantes centroamericanos, sabiendo que los mexicanos sufren iguales tratos, cuando van de manera ilegal a vecino del norte. No hay una explicación lógica para eso, pero ese comportamiento de México justifica las afirmaciones de padre Alejandro Solalinde, al referirse al gobierno mexicano como "administrador" de Estados Unidos. Así, al tiempo que México se dobla delante del gobierno norteamericano, frente a los países centroamericanos, se presenta grande, rico, poderoso, tratando a sus vecinos como periféricos, en su gran patio trasero.

Es interesante observar el papel que juega México en este contexto y los reflejos que tiene eso en la vida cotidiana de los personajes migrantes centroamericanos en la novela, al hacerse pasar por mexicanos para llegar al país del Norte. Este imaginario revela un deseo contradictorio. El sueño de los personajes es no ser vistos, sobre todo por las autoridades migratorias, los secuestradores y la policía en su paso por México. Una contradic- ción comprensible dado el contexto en el que se encuentran: Al mismo tiempo que desean ser invisibles para no sufrir humillaciones y maltratos en el territorio mexicano, saben que una de las principales tácticas de sobrevivencia para cruzarlo es hacerse pasar por mexicano:

Entonces el chiste, pensaba yo en las noches, el chiste es ser invisible. Allí está la gracia. Cómo se puede ser invisible. Hay que incurrirse en el día, meterse en las sombras en la noche. Para avanzar por el territorio mexicano hay que caminar, sonreír como mexicano, aprenderse de nombre del presidente de México, el himno nacional de México, la bandera de México. Dicen que esto te preguntan los mexicanos cuando tienen duda y tú estás allí, jurando que eres mexicano. Al tío Braulio, que en su tercer intento logró llegar a los Estados Unidos, lo agarraron los gringos en la franja fronteriza. Dijo que era mexicano para que los gringos lo dejaran nada más en la frontera norte de México... [...] Hernández: 2013; 38)

Quién sabe, dicen que aquí no se sabe, que de pronto empezás a ver letreros de Tenosique. Así, sin una bienvenida, pregunta Charles, juguetón. Los mexicanos te dan la bienvenida a su manera, dije. Ojalá ni nos vean. Eso es que no nos vean. Invisibles, pensé, siempre se llega al mismo anhelo: ser invisibles (Ibíd.; 197)

[...] Qué le pedirá a las autoridades mexicana. Nada más que no nos vean [...] (Ibíd.; 302) 
Ser invisible es una "táctica de sobrevivencia"8 usada por los migrantes, pero en México es una tarea casi imposible, porque todos están expuestos y vulnerables. Por más que intenten ocultarse, siempre deben enfrentarse con algún grupo de mexicanos que quiere sacarles ventajas, sean los grupos criminales o las autoridades. Los migrantes son vigilados por estos grupos, impidiéndoles la mayor parte de las veces, cruzar México sin ser vistos por ellos. En este sentido, de la misma manera que a muchos migrantes mexicanos, les gustaría pasarse por gringos para entrar a los Estados Unidos, a muchos migrantes centroamericanos les gustaría pasarse por mexicanos para cruzar México hacia la frontera norte.

Ocultar la identidad, no es una tarea fácil. En primer lugar, se debe de imitar el acento, mexicano, "cantadito" como afirma uno de los personajes, porque los centroamericanos, aunque compartan muchos rasgos lingüísticos y culturales con México, tienen sus propias formas (acentos) de hablar el español. En segundo lugar, ocultarse, pasarse por mexicano, conlleva un serio problema identitario. Decir que es mexicano, cuando en realidad son hondureño, salvadoreño, nicaragüense o guatemalteco, significa negar lo que hay de sagrado para estos migrantes, sus orígenes, pues a pesar de los problemas que enfrentan en sus países, sienten orgullo por su patria. Pasarse por mexicano, significa negar su propia identidad, por tanto negarse a sí mismo como sujeto.
Aunque es bueno subrayar que se trata de una táctica de sobrevivencia coyuntural, pasajera.

A lo largo de la narrativa, México es representado siempre como una barrera, y como un espacio de violencia que los personajes que intentan cruzar su territorio, enfrentan. Se observa que los mexicanos, en ningún momento dudan en aplicar métodos de violencia en contra de los migrantes pobres. Al contrario de la novela La mara, donde los mareros son los grandes villanos, en su mayoría centroamericanos, a los que no les importa practicar todo tipo de violencia con su propia gente, en Amarás a Dios sobre todas las cosas, el gran problema para los migrantes son los mexicanos. En este sentido, considerando que en toda novela hay un antagonista y un protagonista, en Amarás a Dios sobre todas las cosas el antagonista del sujeto migrante son los mexicanos; en La mara ${ }^{10}$, son los mareros, sus propios coterráneos.

Como se señala en toda la novela, México aparece como el villano, que deben enfrentar los migrantes centroamericanos. Si se observamos en entrelíneas, se puede dar cuenta, que por detrás de este villano hay uno mucho más grande y más poderoso: los Estados Unidos. En esta perspectiva, los personajes cuestionan el comportamiento de México en relación a ellos, preguntándose -como lo hacen a menudo-- si los gringos no están detrás de ese comportamiento:

\footnotetext{
8 Tatica de sobrevivencia - así como estrategia de sobrevivencia son conceptos desarrollados por el investigador francés Michel Certeau (1998:92). Para él las taticas de sobrevivencia son usadas por los más débiles con el propósito de salir de la pobreza, de la subordinación en las que se encuentran. Mientras tanto, las estrategias de sobrevivencia son usadas por los poderosos para mantenerlos sometidos.

9 Hablar cantadito como los mexicanos - A lo largo de la novela se puede observar, en el discurso de los personajes, su preocupación en "hablar cantadito como los mexicanos". Lo señalamos como un sintagma ideológico, importante en esa especie de simulación identitaria que actúa como táctica de sobrevivencia, aunque no es nuestra intención analizar las variedades lingüísticas mexicana, que sería más propio de un estudio de lingüística dialectal. 10 La novela La Mara, del escritor mexicano Rafael Ramírez Heredia, tiene también como eje la migración centroamericana hacia los Estados Unidos en su paso por México. En dicha novela el gran villano de los migrantes centroamericanos son las maras, contrario Amarás a Dios sobre todas las cosas, donde el terror de los migrantes centroamericanos son los secuestradores mexicanos. Cabe recalcar que la novela referida también forma parte del corpus de nuestra tesis doctoral.
} 
Vos por qué crees que los mexicanos son duros con nosotros dice pronto Elena. No sé. Pero por qué crees. Pues, a lo mejor porque los gringos son duros con ellos. También lo son con nosotros. Sí, pero nosotros no tenemos con quien desquitarnos. Y creo que son así porque es como una ley de la vida: los de arriba se enseñan con los de abajo: ellos debajo de Estados Unidos, nosotros debajo de ellos. A lo mejor son los gringos los que les exigen que no nos dejen pasar. México es como una frontera para nosotros, una frontera larga y tirada, en medio de nuestros países y Estados Unidos. Una frontera larguísima. Imagínate que un día los mexicanos se levantaran y dijeran Nos acabamos de dar cuenta de que lo único que quieren los centroamericanos es pasar, así es que vamos a dejarlos pasar [...] (Hernández: 2013; 112)

Los migrantes centroamericanos no tienen con quién desquitarse de lo que le hacen, tampoco tienen fuerza suficiente para enfrentarse a México, representada en sus instituciones, políticas y grupos sociales, delincuenciales. Mucho menos a los Estados Unidos y sus representantes. México sí puede arremeter, en forma de desquite, con los migrantes centroamericanos indefensos en su territorio. Cabe subrayar en este punto, el contraste entre el papel que México ha desempeñado en el contexto, en relación a la migración de sus compatriotas, hacia los Estados Unidos y el trato que le da los vecinos dentro de su territorio.

Cuando el tema es la migración mexicana hacia los Estados Unidos, los primeros critican a los Estados Unidos y lo ven injusto, cruel la actitud de los segundos. Sin embargo, cuando el asunto son los migrantes centroamericanos en su territorio, la cosa cambia.

Lo anterior queda evidente en la novela, cuando los migrantes son secuestrados por un grupo criminal mexicano. Este es el momento más duro en el cual se reelabora la relación cotidiana entre los migrantes centroamericanos y los mexicanos. El secuestro representa el ápice de esta relación, mostrando toda su complejidad, por la forma como toda la acción se desarrolla. En este sentido, todo es tan bien planeado por los secuestradores, que los personajes tardan para descubrir que cayeron en una trampa, que han sido secuestrados. En algunos pasajes de la novela, la presencia de la crueldad se exacerba:

[...] Miren, cabrones, dijo una voz, ya para entonces reconocida, ustedes son unos hijos de puta que se meten a un país como ladrones. Y nosotros qué, estamos pintados, o qué. Vamos matar a uno para que anden contando que matamos a uno. Eso es lo que le gusta, no. Contar lo que les pasa Maricones $[\ldots]$

[...] El jefe dijo Miren, hijo de la chingada, acabo de hablar con Dios. Me dijo que los va a dejar ir, que se van a estar calladitos, que se van a portar bien. Así me dijo. Dónde está el que se alebrestó. Aquí. (Hernández: 2013; 199)

Hasta este momento los migrantes no saben que han sido secuestrados, aunque estén seguros de que algo malo ha pasado. Observamos el cinismo y la violencia con que los secuestradores tratan a estos personajes. Los insultan, los acusan de ladrones, cuando ellos son los verdaderos ladrones. Aquí es interesante el juego que el autor 
hace con la cuestión religiosa, "acabo de hablar con Dios". En otras palabras, significa que tiene la autorización de Dios para hacerles lo que les dé la gana. En este contexto, cabe señalar la manipulación que los secuestradores hacen con la figura de Dios ${ }^{11}$ ante los migrantes, siendo la intención, sacarle lo único que les resta: su fe de saber que Dios está con ellos.

Paradojas de la historia, los conquistadores y colonizadores europeos tuvieron en la figura de Dios, a un gran aliado para concretar sus objetivos en América, en la historia reciente, como el contexto colombiano, los sicarios se encomiendan a Dios y la Virgen ${ }^{12}$ para cometer con éxito -si se puede usar esta palabra-- sus crímenes.

En la secuencia narrativa, los secuestradores, de manera particular, el "jefe" del grupo, justifican su violencia por medio de acusaciones:

[...] Ustedes vinieron a México por su gusto, nadie los metió a México a la fuerza. Pues ahora se chingan. Este tren es el expreso, y en el expreso mando yo. Y del expreso nadie se bajar, oyeron, putos. Me cagan sus lloriqueos, me cae. Se acabó la chingadera, okey, se acabó. Así, o más claro. Bueno, más claro, hijos de la chingada: ustedes vienen secuestrados. Óiganlo para que no anden de mamadas: secuestrados. $\mathrm{Y}$ el que se quiere ir, paga. El que no paga, se chinga, esa es la ley, culeros (Hernández: 2013; 218)
Durante los días en cautiverio, la situación de los migrantes va empeorando y el sentimiento de odio México-Centroamérica aparece de manera acuciante. El discurso de sentido común, acerca de las razones de la salida de los migrantes de sus países, es reelaborado por la voz narrativa de una manera muy expresiva, porque es un discurso que se encuentra en los diferentes países que reciben migrantes: "salen porque quieren". Ese discurso de ver al otro como invasor, es común en el mundo migrante y bien representado en la obra por Hernández. Cabe señalar, el discurso dirigido a Walter y a los demás migrantes que lo acompañan, es repetido en otro grupo de migrantes en cautiverio. Se recrimina, como ustedes dejaron sus países por "gusto", por "ladrones", "perezosos", "huevones", "abusivos", tendrán que pagar, de otra forma estarán todos muertos:

[...] A ver, cabrones, los que acaban de llegar, para entendernos. Ustedes están aquí por huevones, por no querer trabajar en sus países, por creer que este país es su patio, por abusivos y ladrones, pero eso ya ni modo, se chingaron. Ahora a nuestro negocio: ustedes están secuestrados y nadie se va a ir hasta que sus piches familias, que los han de querer porque les aguantan sus pendejadas, paguen lo que deben. Todos van a pagar o se chingan. Aquí el que no paga se muere. No los vamos a estar manteniendo, bola de putos. Pagan y se largan, no pagan y se mueren, así de claro. El hombre grande

\footnotetext{
11 Esta discusión es presentada en el capítulo IV de la novela, el cual tiene como título: "Aquí no existe Dios (Hernández: 2013; 198)". Aunque los migrantes, en la mayor parte de la narrativa, dejen muy clara su fe en Dios, en este capítulo el nivel de violencia llevado a cabo por los secuestradores es tan grande que algunos empiezan a dudar de su existencia.

Cabe recalcar que el Dios de los migrantes no es el Dios de los poderosos sino el Dios de la esperanza, el Dios de los pobres. En este sentido, podemos interpretar, reescribir el sintagma "Sobre todas las cosas" entendiendo que ese "sobre todas las cosas" significa, precisamente, a pesar de todas las cosas, esto es, de todas las desgracias, los sufrimientos, las aventuras que tienen que pasar. Entonces Dios aparece como un sostén, una esperanza a pesar de todo, de ahí el título Amarás a Dios sobre todas las cosas.

12 Nuestra Señora Auxiliadora - también conocida en Colombia como La Virgen de los Sicarios es santa patrona de una famosa iglesia en Medellín donde los sicarios y otros criminales van a pedir bendiciones para que todo salga bien con los crímenes que cometen. El libro del escritor colombiano, Fernando Vallejo, La Virgen de los Sicarios es una referencia directa a todo el contexto en el que están involucrados los sicarios en Colombia.
} 
tomó aire. Yo soy la ley, hijos de la chingada, y con mi pinche ley no se juega [...] (Ibíd.; 234)

[...] ustedes son un chingo y nosotros no somos el gobierno para mantenerlos. Nada más una vez se los voy a decir, hijos de la chingada, o pagan o se mueren, y si alguien tiene una pregunta se la mete por el culo que aquí no es escuela [...] (Ibíd.; 235)

La violencia es de una crueldad tan grande que solo la literatura ${ }^{13}$ es capaz de describirla con tanta propiedad. Esta violencia es reelaborada de una forma muy vívida en la novela. Cuanto más avanza la narrativa, más la violencia se exacerba en todos los sentidos. Lo único que le resta a los migrantes, es pedir ayuda a Dios, pero de inmediato son confrontados por las palabras de uno de los secuestradores, quien les recuerda: donde están no hay Dios, que él es Dios:

[...] Una mujer, de cuarenta o cincuenta años, se levantó, inclinó la cabeza: Señor Dios, pon una gota de compasión en estos hombres y. Dios, repitió el hombre grande, Dios, y avanzó pisando a los migrante hasta donde estaba la mujer. Levantó la mano derecha y le dio una bofetada brutal. Dios, cabrones. Aquí no existe Dios, hijos de la chingada.

[...] Aquí Dios soy yo, méndigo. Su Dios no existe, animales. Milagrosamente la mujer seguía de pie y parecía seguir rezando. El hombre volvió hasta el frente. Me reemputa que salgan con mamadas. Sépalo para que no pierdan el tiempo en oraciones. Aquí no existe Dios (Hernández: 2013; 243)

Durante el cautiverio, uno de los momentos más tensos, es cuando Walter, Gigante y El Profeta huyen en buscar ayuda. El primer problema que enfrentan es un muro de alambre que tienen que saltar. En el intento, son perseguidos por algunos de los secuestradores, quienes matan a Gigante. Desesperados, Walter y El Profeta siguen huyendo y logran escapar. Mientras caminan en busca de ayuda, vuelven a preguntarse acerca del tratamiento que los mexicanos les dan. Lo que llama más la atención en la conversación, entre los dos personajes, es cuando se refieren a los papeles, los documentos. La falta de estos "papeles" es lo que los ha llevado a esta situación extrema:

[...] Por qué nos persiguen tanto, le pregunté al Profeta cuando nos alejamos de la última casa y empezamos a sentir el alivio de salir de aquella población de adobe. Porque ya no estamos en nuestra tierra y todavía no llegamos a la que queremos llegar. Nada hay más vulnerable que el que camina. El odio, dije, por qué tanto odio. No es odio, sino ganas de joder al que no existe. Existimos vos y yo, Profeta, pregunté de veras, sin ganas de retórica. Los transmigrantes no existen, aquí somos nada. Nuestros afectos están lejos y en ningún lado nos espera ningún afecto, estamos en el vacío. Si el gobierno mexicano nos dejara pasar, no tendríamos que aguantar tantas calamidades, dije, somos botín de todos porque somos y nos sentimos clandestinos, que le costaría al

\footnotetext{
13 Cabe señalar que junto con la producción novelística hay una producción audiovisual muy importante dedicada al tema de las migraciones centroamericanas, entre ella las películas: "Sin nombre (2009); "La breve y precoz vida de Sabina Rivas" (2012), basada en novela "La mara", mencionado anteriormente. Cabe mencionar también "La jaula de oro" (2013). Documentales: "Los invisibles" (2010); "La bestia" (2010) y "La vida en tierra ajena" (2017). Sin embargo, el objetivo de este artículo no es la producción audiovisual sino la novela Amarás a Dios sobre todas cosas, en particular.
} 
gobierno mexicano dejarnos pasar. Le costaría un regaño de los gringos y no faltarían mexicanos que protestaran. Lo que son los papeles, dije. Por estos tiempos son más importantes los papeles que los hombres, dijo El Profeta. Una lagartija pasó de largo y un cuervo se acomodó para mirarnos. Cargamos una falta grave, dijo el Profeta, andar en país ajeno sin permiso, eso se paga. De sobra, dije (Hernández: 2013; 284)

Walter y El Profeta no están en su tierra, pero tampoco alcanzaron su destino. Están atrapados en un lugar desconocido, donde son visibles físicamente, pero invisibles socialmente. Son sujetos socialmente inexistentes, sobre todo para los delincuentes y las autoridades mexicanas. La forma cruel en que son tratados, hace que Walter se auto refiera como sujetos inexistentes. Cabe señalar, la 28 falta de documentos es la justificación principal de gobiernos de países receptores o de tránsito como México, para perseguir a los migrantes. En este sentido, son sabias las palabras del personaje El Profeta quien a afirmar que los papeles son más importantes que los hombres: andar sin dichos papeles es una falta por la cual se paga muy caro.

Toda esa conversación entre Walter y El Profeta se desarrolla por el camino, mientras buscan ayuda para sacar a sus compañeros del cautiverio. El camino es largo y aunque indiferentes, la gente los ve pasar, pese al esfuerzo por no ser vistos. Una señora les permite entrar a su a casa ofreciéndoles agua, es la única ayuda que les da, pidiéndoles que se vayan de inmediato. En realidad, ellos creían que les ayudaría a encontrar un puesto de la policía. El comportamiento de este personaje en relación a Walter y al Profeta es de una frialdad sin medida, pero al mismo tiempo muestra el terror y el miedo en que vive mucha gente en la zona.

Después de caminar por mucho tiempo, Walter y El Profeta encuentran al ejército que rescata a sus compañeros del cautiverio. Estos son encontrados en condiciones lamentables de vida:

[...] Si esto apesta a mierda, me contó Luis, es porque muchos nos cagamos pensando que nos iban a matar. Por eso estamos todos batidos, dijo Trojan. Por eso los soldados les dijeron a los migrantes que se metieran a la regadera, que estaba en el cuarto por el que todos habíamos pasado y habíamos padecido humillaciones y golpes. Nada más un minuto por cada uno, ya luego se bañan bien, decía el oficial (Hernández: 2013; 290291)

[...] los migrantes lloraban al salir, se llenaban los pulmones de aires y se quedaban con la sonrisa atorada. Ni siquiera se daban permiso de gritar, de mostrar su alegría. Los reprimía el dolor, tantos días de medo y sangre. Salieron formados, con lágrimas o sin ellas, con una expresión de incredulidad y duda. Hoy, le decía yo a uno y otro, si ya estás libre, manda al carajo tus demonios. Pero yo mismo no podía sentir alegría (Ibíd.; 291)

[...] Muchos migrantes llevaban el torso desnudo, la piel amoratada. Una franja oscura constataba los golpes de tabla. Algunos habían adelgazado hasta parecer solo estructuras óseas. Otros miraban con ojos redondos, la piel estirada. Todos iban descalzos. Había mujeres y niños, el horror en la cara. Al poner el pie en el estribo un 
hombro cayó fulminado. Vivo un segundo antes, cuando su pecho dio en tierra estaba muerto. Los soldados levantaron al hombre que había perdido la vida por la emoción de salvarla (Ibíd.; 291)

Al detenerse en esta parte de la novela, se siente la impresión de estar frente a un relato de horror, visto únicamente en las películas. En este momento volvemos al título del IV Capitulo de la novela, Aqui no existe Dios. Si Dios existe o no en situaciones como estas, no es lo fundamental en nuestro análisis, lo principal es mostrar a qué extremos han llegado las relaciones entre México y Centroamérica, a partir de la experiencia de la migración, tan bien reelaborada en Amarás a Dios sobre todas las cosas.

\section{Conclusión}

Amarás a Dios sobre todas las cosas es una novela sobre multilingüismo, no-sedentarista y, por lo tanto, muy importante para entender los diversos movimientos entre lo global y lo local de los procesos migratorios. En este sentido, la novela aporta una nueva visión en el contexto de la narrativa literaria sobre las migraciones y la importancia que tiene, permitiendo una aproximación local y global de toda la problemática en la que están involucrados los migrantes centroamericanos en su paso por el territorio mexicano. El eje central de la obra es la migración centroamericana hacia los Estados Unidos. La reelaboración de esta problemática puede ser aplicada a situaciones vividas por millares de migrantes en otras partes del mundo. Por ello, se ha intentado demostrar en este trabajo, que las relaciones a lo largo de la historia, entre México y Centroamérica, de manera particular, relativas al contexto de las migraciones, han tomado dimensiones críticas y la novela Amarás a Dios sobre todas las cosas, en particular, narra de forma excepcional, los rumbos que estas relaciones han alcanzado en los últimos años.

La problemática en la que han estado involucrados los procesos migratorios, no únicamente en el contexto tratando en la novela, sino a nivel mundial, ha mostrado en realidad, que el fenómeno de la globalización promueva el cierre de las fronteras en diversos países del mundo. Se tenía la expectativa que los procesos de globalización mejorarían el mundo, la experiencia ha mostrado lo contrario. Al respecto Homi Bhabha (2013:51) apunta:

El carácter inestable de este estatus de interno o externo de las minorías a menudo se traduce en la restricción de derechos y la representación en nombre de la existencia de un enemigo interno, considerando un peligro que ha cruzado la frontera desde exterior carente. El dominio de la "seguridad insegura" no solo representa la "perversión" de la forma de gobierno democrática: el aparato de seguridad da cuenta de los límites de la alteridad de la nación, la frontera de ese doble agónico de la democracia.

Vistos como un peligro que ha cruzado la frontera, los migrantes centroamericanos en México, son tratados partiendo del discurso de la seguridad. Todos los planes y proyectos mencionados a lo largo de este texto, ejemplifican muy bien lo que representa ese discurso. En este sentido, podemos mencionar a los personajes de la novela, que mueren durante el trayecto en territorio mexicano, como lo rubrican los propios informes de la Comisión de Derechos Humanos, sobre la 
situación de los migrantes centroamericanos a su paso por México. La masacre de San Fernando (2010) en la cual fueron asesinados 72 migrantes latinoamericanos de distintas nacionalidades, es un ejemplo claro que el discurso de un mundo sin fronteras, propagado por la globalización, es fallido.

\section{Bibliografía}

Anguiano Téllez, María Eugenia. (2010). Las políticas de control de fronteras en el norte y en el sur de México. Anguiano Téllez, María Eugenia y López Sala, María Ana (Eds.). Migraciones y fronteras: Nuevos contornos para la movilidad internacional. Barcelona: Editorial Icaria.

Becker, Udo. (2007). Dicionário de simbolos. Trad. Edwino Royer. São Paulo: Editora Paulus.

Bhabha, K. Homi. (2013). Nuevas minorías, nuevos derechos: notas sobre cosmopolitismos vernáculos. Buenos Aires: Siglo Veintiuno Editores.

Cuevas Molina, Rafael. (2015) Entrevista. Heredia Cros, Edmond. (2002) El sujeto Cultural. Medellín: Fondo Editorial Universidad EAFIT.

García, Mercedes. Alianza Para la Prosperidad: Muy lejos de ser una solución definitiva para la crisis migratoria del Triángulo Norte en Centroamérica. (en línea). [Honduras, 22 de febrero de 2017:http://www.coha.org/alianza-para-la-prosperidad-muy-lejos-de-ser-una-soluciondefinitiva-para-la-crisis-migratoria-del-triangulo-norte-en-centroamerica [Consulta: 20 de noviembre 2016]

García Sandoval, Carlos. No más muros: exclusión y migración forzada en Centroamérica. (2015). San José: Editorial Universidad de Costa Rica.
H. AMORETTI, María. (1992). Diccionario de términos asociados en teoría literaria. San José: Editorial Universidad de Costa Rica.

Hernández, Alejandro. (2013). Amarás a Dios sobre todas las cosas. México: Editorial Tusquets

Martínez, Óscar. (2010). Los migrantes que importan: En el camino con los centroamericanos indocumentados en México. Barcelona: Escaria Editorial.

Ribolt Toussaint, Mónica. México en Centroamérica: del activismo de los años ochenta a la nueva agenda del siglo XXI. [en línea). [Costa Rica, Cuadernos Intercambio sobre Centroamérica y el Caribe vol. 11, núm. 1, enero-junio, 2014://http://www.redalyc. org/pdf/4769/476947241009.pdf [Consulta:_15 marzo de 2017]

Sozono Solalinde, Juan Manuel Alejandro. Urbano, Javier. \& Massis, Gerald. "Migración: una crisis bumanitaria. (En línea). [México, Conferencia presentada en la Feria Internacional del libro de Guadalaja, 17 de junio de 2016:// https://www.youtube.com/watch?v =NldMsfVmoKY\&t=11s [consulta: 10 de marzo de 2017]" 